\title{
Leprosy and the Community
}

\author{
LEPRA ANNUAL REPORT 1975
}

The 51 st Annual Report of LEP.RA condenses into relatively few pages packed with information a notable contribution to the cause of leprosy control during 1974 , and reveals the concern of very many people all over Britain. Income during 1974 rose to a record $£ 447,884$, and made it possible to increase the amount spent on grants and services to leprosy work by $£ 78,000$ above the record figure achieved in 1973.

For over 50 years the declared objective of LEPRA has been the eradication of leprosy. At present its main guidelines towards this objective are: leprosy research and the dissemination of information; prevention and cure of leprosy in children; the training provision and support of indigenous medical staff workers; assistance to governments and other organizations in support of effective leprosy work; and integrated control schemes providing domiciliary treatment. All this is offered on a totally non-sectarian basis.

During 1974 the increasing concern of LEPRA with research made possible the importation of 20 armadillos into Britain and their continuing study as well as the support of a series of other research projects. Assistance in the care and treatment of children was given to 97 centres mostly in Africa and Asia. The comprehensive leprosy control project in Malawi now enters its tenth and final year, with $\mathrm{Dr}$ Molesworth, O.B.E., now Adviser to the Malawian Government for Leprosy Control. The original project has led to nation-wide developments and demonstrates successfully how leprosy can be tackled when government and voluntary agencies are able to co-operate fully. The involvement of LEPRA in control schemes in Sierra Leone, Uganda, Zambia, Ethiopia, Guyana and India continues. In India and Indonesia support is given to multipurpose rural health projects. The training of indigenous medical and other staff has been encouraged.

Last, but not least, this Journal has been sustained and its expansion in both size and subsidized distribution made possible. We join with numerous supporters and well-wishers in congratulating LEPRA on a year of outstanding progress. Long may its beneficent work continue. 


\section{LEPROSY MISSION CENTENARY ANNUAL REPORT}

"A YEAR OF GRACE", the Annual Report of The Leprosy Mission for 1974, its Centenary Year, reveals both the astonishing breadth of the Mission's activities and the depth of concern for leprosy sufferers and the control of leprosy felt by Christian communities in many countries. The Mission, now very much an international organization, enjoyed a record income of $£ 1,486,111$ in 1974 , an increase of $£ 340,000$ over 1973, and this, in spite of inflation, enabled the extensive work of the Mission in Asia and Africa to be sustained and developed.

India was the scene of the pioneer early work of the Mission, and is still the country where its most extensive and concentrated work is undertaken. The wellknown research and training centre at Karigiri continues to develop. It was the historic work of Paul Brand on the cure and prevention of deformities in leprosy which gave this centre its international reputation, and with the appointment of Dr Fritschi as Superintendent, this aspect will certainly be carried forward. The large-scale leprosy control project in Gudiyatham Taluk among a population of 400,000 is now coming to its years of fruitful assessment, and leprosy workers everywhere in Asia await the findings with interest. At many centres elsewhere in India the concern of the Mission for the individual patient is an object lesson to all. Community concern and closer co-ordination with Government are signs of health and progress.

In East and South East Asia, the phasing out of Hay Ling Chau, the "Isle of Happy Healing", with leprosy sufferers integrated into general medical work marks a new stage in leprosy control in Hong Kong, and has enabled Dr Grace Warren to undertake a wider role as Adviser in reconstructive surgery throughout Asia. In Korea, Thailand, Indonesia and New Guinea there are important developments in integrated co-operation with Government Health Service.

In many countries in Africa the Mission has a long tradition of co-operation with a wide variety of national Churches and Missions, and thanks to its support, leprosy control has advanced and large numbers of patients have been encouraged. Further developments are now planned in Zaire.

With its enlightened policies, its international outlook and the breadth of its interest, the Mission never forgets "the one, and the one, and the one," a principle which comes out so clearly in the Report. We offer all concerned our good wishes for 1975 . 